\title{
The pharmacokinetics of enteral antituberculosis drugs in patients requiring intensive care
}

\author{
C F N Koegelenberg, ${ }^{1} \mathrm{MB}$ ChB, MMed (Int), FCP (SA), MRCP (UK), Cert Pulm (SA), PhD; A Nortje, ${ }^{1}$ MB ChB, FCP (SA), MMed (Int); \\ U Lalla, ${ }^{1} \mathrm{MB}$ ChB, FCP (SA); A Enslin, ${ }^{1} \mathrm{MB}$ ChB, MMed (Int); E M Irusen, ${ }^{1} \mathrm{MB}$ ChB, FCP (SA), PhD; B Rosenkranz, ${ }^{2} \mathrm{MD}, \mathrm{PhD}, \mathrm{FFPM}$; \\ H I Seifart, ${ }^{2} \mathrm{PhD}$; C T Bolliger ${ }^{1} \mathrm{MD}, \mathrm{PhD}$ (deceased)
}

${ }^{1}$ Division of Pulmonology, Department of Medicine, Stellenbosch University and Tygerberg Academic Hospital, Tygerberg, Western Cape, South Africa ${ }^{2}$ Division of Pharmacology, Department of Medicine, Stellenbosch University and Tygerberg Academic Hospital, Tygerberg, Western Cape, South Africa

Corresponding author: C F N Koegelenberg (coeniefn@sun.ac.za)

Background. There is a paucity of data on the pharmacokinetics of fixed-dose combination enteral antituberculosis treatment in critically ill patients.

Objectives. To establish the pharmacokinetic profile of a fixed-dose combination of rifampicin, isoniazid, pyrazinamide and ethambutol given according to weight via a nasogastric tube to patients admitted to an intensive care unit (ICU).

Methods. We conducted a prospective, observational study on 10 patients (mean age 32 years, 6 male) admitted to an ICU and treated for tuberculosis (TB). Serum concentrations of the drugs were determined at eight predetermined intervals over 24 hours by means of highperformance liquid chromatography.

Results. The therapeutic maximum plasma concentration $\left(\mathrm{C}_{\max }\right)$ for rifampicin at time to peak concentration was achieved in only 4 patients, whereas 2 did not achieve therapeutic $\mathrm{C}_{\max }$ for isoniazid. No patient reached sub-therapeutic $\mathrm{C}_{\max }$ for pyrazinamide $(6$ were within and 4 above therapeutic range). Three patients reached sub-therapeutic $\mathrm{C}_{\max }$ for ethambutol, and 6 patients were within and 1 above the therapeutic range. Patients with a sub-therapeutic rifampicin level had a higher mean Acute Physiology and Chronic Health Evaluation II (APACHE II) score ( $p=0.03)$ and a lower estimated glomerular filtration rate (GFR) $(p=0.03)$.

Conclusions. A fixed-dose combination tablet, crushed and mixed with water, given according to weight via a nasogastric tube to patients with TB admitted to an ICU resulted in sub-therapeutic rifampicin plasma concentrations in the majority of patients, whereas the other drugs had a more favourable pharmacokinetic profile. Patients with a sub-therapeutic rifampicin concentration had a higher APACHE II score and a lower estimated GFR, which may contribute to suboptimal outcomes in critically ill patients. Studies in other settings have reported similar proportions of patients with 'sub-therapeutic' rifampicin concentrations.

S Afr Med J 2013;103(6):394-398. DOI:10.7196/SAMJ.6344 


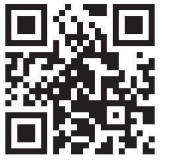

The global increase in the incidence of tuberculosis (TB), especially in conjunction with the HIV pandemic, has resulted in an increased number of hospital admissions due to TB. ${ }^{[1]}$ Previous studies have shown that approximately $1.5 \%$ of hospitalised adults with active TB develop respiratory failure requiring admission to an intensive care unit (ICU) ${ }^{[2,3]}$ Mortality among these patients can be as high as $65 \% .^{[4]}$

A myriad of factors may influence pharmacokinetics in patients admitted to the ICU. Drug absorption is generally decreased. Tarling and co-workers found sub-therapeutic plasma levels of enterally administered paracetamol, and showed that gastric emptying time varied significantly between patients. ${ }^{[5]}$ Patients in the ICU often have increased vascular permeability secondary to cytokine release, as well as hypo-albuminaemia, which alter the volume of distribution. ${ }^{[6]}$ Furthermore, drug metabolism and excretion may be profoundly affected by hepatic and renal dysfunction. ${ }^{[6]}$

There are also certain factors specific to patients with TB in the ICU that may influence pharmacokinetics, the chief of which is that patients are fed continuously. Drugs are therefore not administered on an empty stomach, as is recommended for some anti-TB drugs to achieve optimal absorption. ${ }^{[7]}$ Interestingly, evidence suggests that the functional absorptive area of the intestines of patients with tuberculosis is also decreased when compared with healthy volunteers, which in turn results in decreased absorption. ${ }^{[8]}$

There are currently no published studies on absorption rates and pharmacokinetic patterns of anti-TB drugs in patients requiring intensive care. The aim of this pilot study was therefore to assess whether therapeutic plasma drug concentrations are achieved following nasogastric administration of first-line fixed-dose combination standard anti-TB treatment in critically ill patients.

\section{Methods}

\section{Study design and patient selection}

All adult patients ( $\geq 18$ years) admitted between April 2010 and June 2011 to the Medical ICU of Tygerberg Academic Hospital (TBAH), Western Cape, South Africa, and treated for pulmonary tuberculosis for at least 7 days were candidates for this prospective observational study, provided a nasogastric tube was in situ on the day of enrolment. Exclusion criteria included the use of concomitant intravenous (IV) TB treatment, an estimated glomerular filtration rate (GFR) of $<50 \mathrm{ml} / \mathrm{min}$, evidence of hepatic dysfunction (alanine transaminase (ALT) or aspartate transaminase (AST) $>3$ times the upper limit of normal), bowel surgery in the preceding 7 days, and pregnancy. TBAH is a 1200 -bed tertiary hospital, one of two academic referral centres in the Cape Town area, and renders a service to a population of approximately 1.5 million. In 2010 the incidence of pulmonary TB in this population was 981 cases per $100000 .{ }^{[9]}$ The Health Research Ethics Committee of Stellenbosch University approved the study. Written informed consent was obtained by proxy on enrolment.

\section{Clinical parameters and general special investigations}

Apart from general demographic information, the number of days on treatment and the presence of co-morbid illnesses and/or sepsis were actively sought. ${ }^{[10]}$ Acute Physiology and Chronic Health Evaluation (APACHE) II scores, ${ }^{[1]}$ the presence of bowel sounds and co-administration of sedatives and inotropic agents were documented on enrolment. As per standard procedure in the unit, 4-hourly gastric aspirates were performed on patients receiving enteral feeds (to measure residual volume). Serum creatinine, bilirubin, ALT and AST were measured, and the GFR calculated according to the Cockcroft and Gault estimation. ${ }^{[12]}$

\section{Administration of antituberculosis medication}

All patients received Rimstar 4-FDC (Sandoz, Kempton Park, South Africa), which is a combination of rifampicin $150 \mathrm{mg}$, isoniazid $75 \mathrm{mg}$, pyrazinamide $400 \mathrm{mg}$ and ethambutol $275 \mathrm{mg}$. The ideal body weight for each patient was calculated according to the Devine formula, ${ }^{[13]}$ and patients were given 2 tablets for weight $<37 \mathrm{~kg}, 3$ for weight 38 $54 \mathrm{~kg}, 4$ for weight $55-70 \mathrm{~kg}$ and 5 for weight $>70 \mathrm{~kg}$. The tablets were crushed and given with $20 \mathrm{ml}$ tap water via a nasogatric tube.

\section{Plasma drug concentration sampling and analysis}

Plasma rifampicin, isoniazid and pyrazinamide concentrations were measured before and 0.5, 1.25, 2.25, 3.5 , 5.0, 12 and 24 hours after drug administration. Blood was collected into $10 \mathrm{ml}$ ethylenediaminetetraacetic acid (EDTA)-containing blood sampling tubes, embedded into crushed ice immediately and transported to the bio-analytical laboratory within 1 hour.

Rifampicin concentrations were measured by means of precipitation of plasma proteins with a mixture of acetonitrile and methanol. Quantification was performed by a high-performance liquid chromatography (HPLC) method in conjunction with triple quadrupole mass spectrometry (MS/MS) detection (quantification range $1-15 \mu \mathrm{g} / \mathrm{ml}$ ). Isoniazid levels were assessed by the precipitation of plasma proteins with $10 \%$ trichloroacetic acid (TCA) solution, followed by derivatisation with $1 \%$ cinnamaldehyde and ultraviolet (UV) detection at $340 \mathrm{~nm}$ (quantification range $1-25 \mu \mathrm{g} / \mathrm{ml}$ ). In the case of pyrazinamide, precipitation of plasma proteins was achieved with $10 \%$ TCA solution; $30 \mu \mathrm{l}$ of the supernatant was injected into the HPLC with UV detection at $269 \mathrm{~nm}$ (quantification range $10-150 \mu \mathrm{g} / \mathrm{ml}$ ). Ethambutol levels were measured by means of precipitation of plasma proteins with acetonitrile at a ratio of plasma/organic solvent of 1:3. Quantification was performed by an HPLC method in conjunction with MS/MS (quantification range $1-15 \mu \mathrm{g} / \mathrm{ml}$ ). The acetylator status of patients for the metabolism of isoniazid was determined by means of phenotyping, and patients were categorised as slow, intermediate or fast acetylators according to accepted criteria. ${ }^{[14-17]}$

Pre-dose concentration, maximum plasma concentration $\left(\mathrm{C}_{\max }\right)$, time to peak concentration $\left(\mathrm{t}_{\max }\right)$ and area under the curve for 24 hours $\left(\mathrm{AUC}_{0-24 \mathrm{~h}}\right.$ ) were documented, and concentrations compared with data from healthy volunteers in the literature. ${ }^{[7]}$

\section{Statistical aspects}

Descriptive statistics and Fisher's exact tests (where indicated) were performed on dichotomous categorical variables, and $t$-tests on continuous data. Unless stated otherwise, data are displayed as means and standard deviations (SDs).

\section{Results \\ Patients}

Over a 1-year period 35 patients admitted to the medical ICU were screened, and the first 10 patients (32 (SD 12) years, 6 male) who fulfilled the criteria entered into the study. Of these, 1 patient died in the ICU. The mean ICU admission duration was 19.9 days (range 6 - 33 days), and the mean APACHE II score was 21 (SD 6). Indications for ICU admission included respiratory failure $(n=8)$, life-threatening haemoptysis $(n=1)$ and a drug overdose $(n=1)$. At the time of blood sampling, all patients required ventilatory support, either invasive $(n=9)$ or non-invasive $(n=1)$. Only 1 patient had feeding interrupted at the time of inclusion and 9 received enteral feeding. None of the study patients had large residual volumes at 4 hours after feeds (mean volume $2.22 \mathrm{ml}$ ), which suggested that gastric emptying was adequate. 


\section{Measured plasma concentrations}

Therapeutic $\mathrm{C}_{\max }$ for rifampicin at $\mathrm{t}_{\max }$ was achieved in only 4 patients (Table 1). Only 2 patients did not achieve therapeutic $\mathrm{C}_{\max }$ for isoniazid, and 5 patients had $\mathrm{C}_{\max }$ levels above the therapeutic range. No patient reached sub-therapeutic $\mathrm{C}_{\max }$ for pyrazinamide, 6 patients falling within and 4 above the therapeutic range. Three patients reached sub-therapeutic $\mathrm{C}_{\text {max }}$ for ethambutol, and 6 patients were within and 1 above the therapeutic range. The acetylator status was slow and indeterminate in the 2 cases in which sub-therapeutic isoniazid concentrations were measured (Table 1). The plasma concentrations over time $\left(\mathrm{AUC}_{0-24 \mathrm{~h}}\right)$ for the various drugs are given in Figs 1 - 4.

Patients with sub-therapeutic rifampicin plasma levels had a significantly higher APACHE II score and a lower estimated GFR than patients with therapeutic levels (Table 2). The low patient numbers precluded similar comparison with the other drugs.

\section{Discussion}

To the best of our knowledge, this is the first study to investigate the pharmacokinetic profile of a fixed-dose combination of rifampicin, isoniazid, pyrazinamide and ethambutol given according to weight via a nasogastric tube to patients with TB admitted to the ICU. In this pilot study we found sub-therapeutic rifampicin levels in more than half of all cases. The other drug components, pyrazinamide in particular, had more favourable pharmacokinetic profiles. Patients with a subtherapeutic plasma rifampicin level had a significantly higher APACHE II score and lower estimated GFR when compared with patients with therapeutic concentrations, but similar gastric emptying.

Rifampicin and isoniazid remain the cornerstone drugs in the treatment of tuberculosis and combination treatment is essential to reduce drug resistance. ${ }^{[18]}$ Of the four first-line drugs, only rifampicin is available as an IV injection in much of the developing world. The pharmacokinetic profile of anti-TB drugs has been extensively investigated outside the intensive care environment. It has been shown that there is a dose-dependent relationship with clinical outcomes in respect of rifampicin. ${ }^{[19]}$ Furthermore, McIlleron and co-workers demonstrated a wide variation in plasma concentrations of rifampicin, with almost $70 \%$ of the study group at the lower end $(<8 \mu \mathrm{g} / \mathrm{l})$ and $22 \%$ at the very low end $(<4 \mu \mathrm{g} / \mathrm{l})$ of the therapeutic range. ${ }^{[20]}$ Kimerling et al. reported very similar findings, $64 \%$ of subjects having levels below $8 \mu \mathrm{g} / \mathrm{l}$ for rifampicin. ${ }^{[21]}$ In a cohort of patients, the majority of whom were HIV-infected, Chideya et al.

Table 1. Therapeutic concentrations $\left(\mathrm{C}_{\max }, \mu \mathrm{g} / \mathrm{ml}\right)$ achieved and acetylator type $(N=10)$

\begin{tabular}{|c|c|c|c|c|}
\hline & \multicolumn{4}{|c|}{ Drug levels achieved } \\
\hline & Rifampicin & Isoniazid & Pyrazinamide & Ethambutol \\
\hline Therapeutic range & $8-24$ & $3-6(A)$ & $20-50$ & $2-6$ \\
\hline \multicolumn{5}{|l|}{ Patient } \\
\hline 1 & 1.2 & $2.4(\mathrm{~S})$ & 29.4 & 2.1 \\
\hline 2 & 7.3 & $3.9(\mathrm{~F})$ & 40.4 & 3.9 \\
\hline 3 & 6.1 & $4.4(\mathrm{~F})$ & 51.0 & 5.0 \\
\hline 4 & 2.8 & $6.2(\mathrm{I})$ & 69.2 & 6.0 \\
\hline 5 & 9.6 & $9.0(\mathrm{~S})$ & 118.3 & 1.5 \\
\hline 6 & 11.7 & 8.7 (I) & 75.4 & 9.0 \\
\hline 7 & 14.1 & 9.7 (I) & 65.2 & 3.0 \\
\hline 8 & 5.6 & $3.5(\mathrm{I})$ & 36.8 & 1.3 \\
\hline 9 & 9.6 & 8.8 (I) & 48.0 & 2.0 \\
\hline 10 & 3.5 & $1.4(\mathrm{X})$ & 30.2 & 1.0 \\
\hline
\end{tabular}

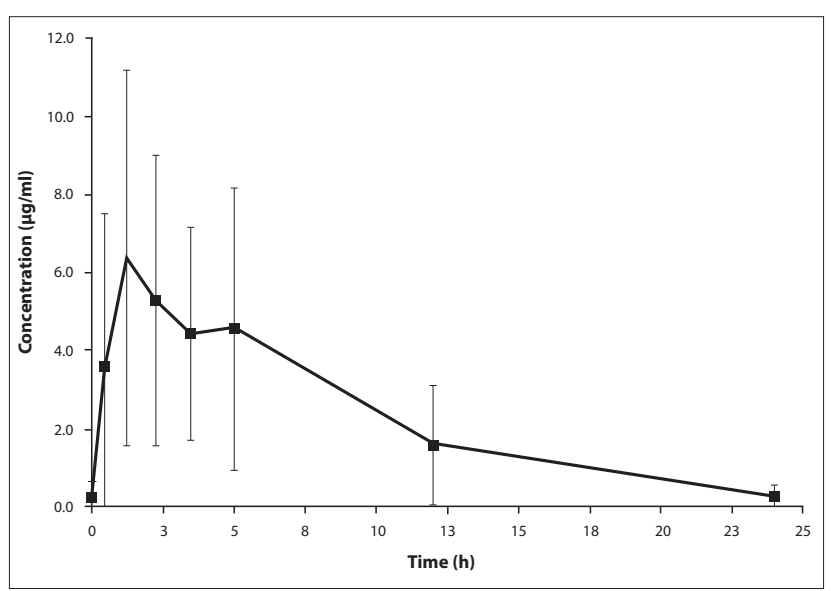

Fig. 1. Rifampicin plasma concentration over time ( 0 - 24 hours, mean (SD), $\mathrm{N}=10) . C_{\max }=6.37 \mu \mathrm{g} / \mathrm{ml}, t_{\max }=1.25 \mathrm{~h}, A U C_{(0-24)}=60.70 \mu \mathrm{g} \times \mathrm{h} / \mathrm{ml}$.

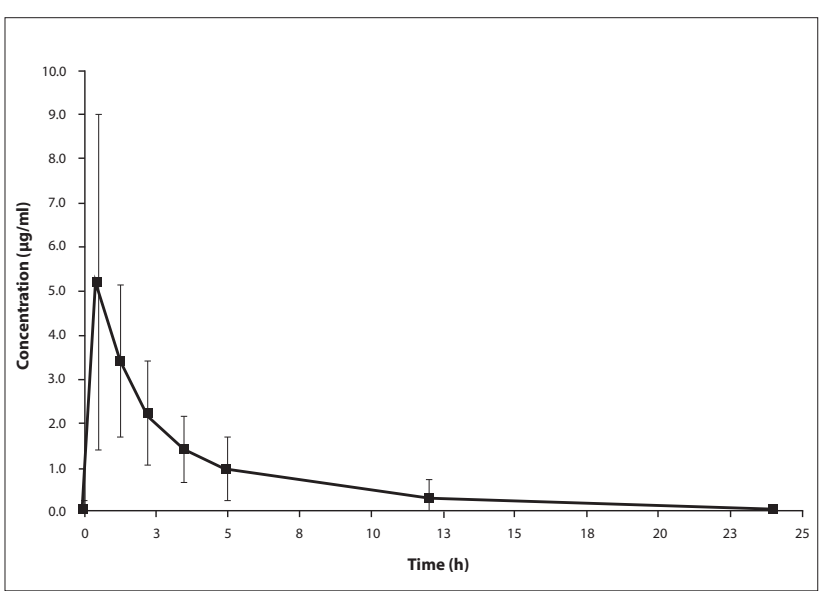

Fig. 2. Isoniazid plasma concentration over time (0 - 24 hours, mean (SD), $\mathrm{N}=10) . C_{\max }=5.20 \mu \mathrm{g} / \mathrm{ml}, t_{\max }=0.5 \mathrm{~h}, A U C_{(0-24)}=19.97 \mu \mathrm{g} \mathrm{x} \mathrm{h} / \mathrm{ml}$. 


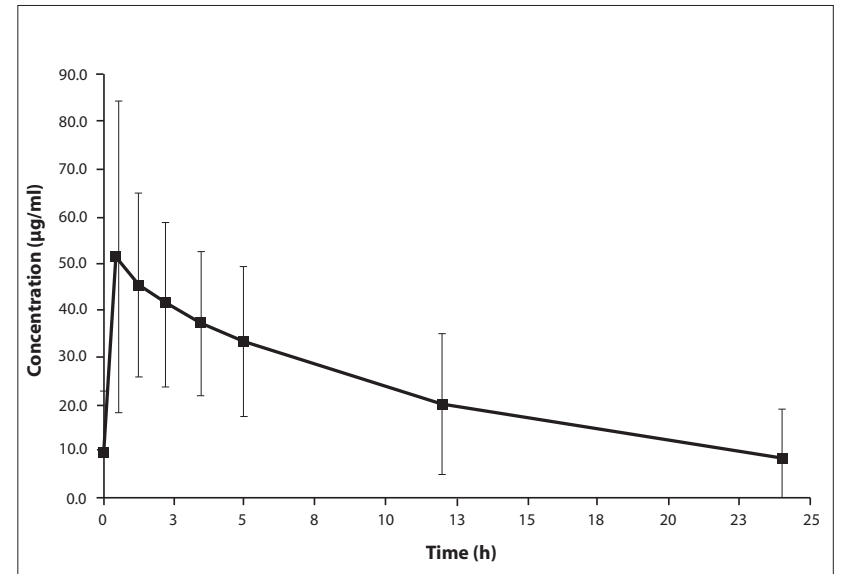

Fig. 3. Pyrazinamide concentration over time ( $0-24$ hours, mean (SD), $N=10) . C_{\max }=51.2 \mu \mathrm{g} / \mathrm{ml}, t_{\max }=0.5 \mathrm{~h}, A U C_{(0-24)}=475.23 \mu \mathrm{g} \times \mathrm{h} / \mathrm{ml}$.

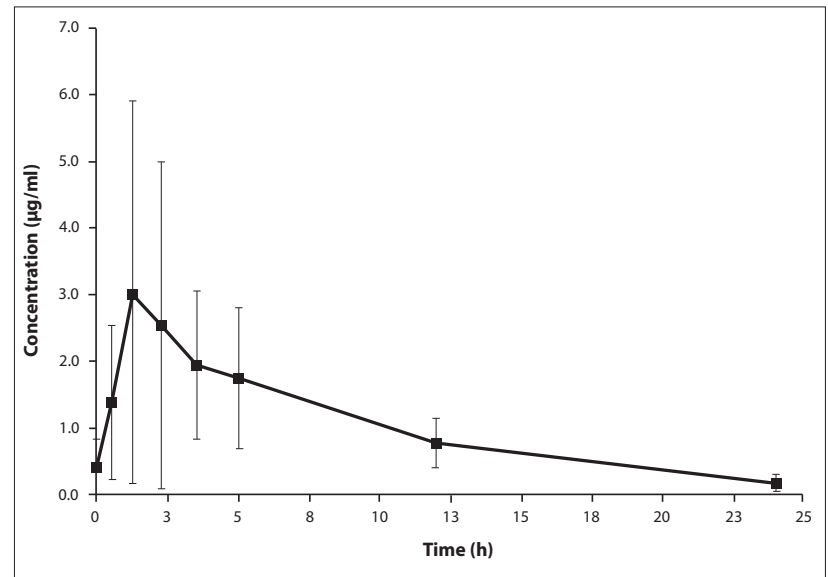

Fig. 4. Ethambutol concentration over time ( 0 - 24 hours, mean (SD), $N=10)$. $C_{\max }=3.02 \mu \mathrm{g} / \mathrm{ml}, t_{\max }=1.25 \mathrm{~h}, A U C_{(0-24)}=26.18 \mu \mathrm{g} \times \mathrm{h} / \mathrm{ml}$.

Table 2. Patients with therapeutic rifampicin plasma concentrations v. patients with sub-therapeutic concentrations

\begin{tabular}{|c|c|c|c|}
\hline & Therapeutic & Sub-therapeutic & $p$-value \\
\hline No. of patients & 4 & 6 & NA \\
\hline Days in $\mathrm{ICU}^{*}$, mean $(\mathrm{SD})$ & $15.5(10.2)$ & $12.0(9.4)$ & 0.59 \\
\hline Days on treatment, mean (SD) & $25.8(24.3)$ & $37.8(69.7)$ & 0.79 \\
\hline APACHE II score, mean (SD) & $16.6(1.7)$ & $25.2(6.1)$ & 0.03 \\
\hline Serum albumin $(\mathrm{g} / \mathrm{l})$, mean $(\mathrm{SD})$ & $25.3(2.2)$ & $25.7(4.2)$ & 0.86 \\
\hline Serum ALT (U/l), mean (SD) & $49.0(55.6)$ & $51.2(30.5)$ & 0.93 \\
\hline Estimated GFR $\left(\mathrm{ml} / \mathrm{min} / 1.73 \mathrm{~m}^{2}\right)$, mean $(\mathrm{SD})$ & $180.0(73.5)$ & $102.3(11.9)$ & 0.03 \\
\hline Inotropic support, $n$ & 0 & 1 & NA \\
\hline IV sedation, $n$ & 4 & 2 & NA \\
\hline Continuous feeding, $n$ & 5 & 4 & NA \\
\hline Nil by mouth, $n$ & 1 & 0 & NA \\
\hline Gastric residual volume $(\mathrm{ml})^{\dagger}$, mean $(\mathrm{SD})$ & $14.0(10.7)$ & $11.5(11.2)$ & 0.73 \\
\hline
\end{tabular}

found that $84 \%$ of patients had levels below $8 \mu \mathrm{g} / \mathrm{l}^{[22]}$ These data are comparable to our findings.

Several mechanisms, which are not necessarily specific to the critically ill patient, may contribute to sub-therapeutic plasma concentrations of rifampicin. Previous studies demonstrated that there is a decrease in functional absorptive area of the intestines in patients with TB. ${ }^{[8,23]}$ This is especially true in patients with multidrug-resistant $\mathrm{TB}^{[23]}$ It has been demonstrated that intestinal paracellular absorption in patients with active pulmonary $\mathrm{TB}$ is markedly decreased, but that this is unlikely to contribute significantly to lower plasma levels, as it represents less than $5 \%$ of the total absorptive area of the small intestine. ${ }^{[2]]}$ The patients in our study group were given rifampicin in a combination tablet either on an empty stomach with the addition of an antacid (sucralfate) or while given continuous feeds. It has been shown that antacids do not influence peak drug levels of rifampicin, but a high-fat meal can reduce $\mathrm{C}_{\max }$ by $36 \%$ and nearly double $\mathrm{t}_{\max }{ }^{[25]}$ The 4-hour nasogastric aspirates are a surrogate marker of gastric emptying, and higher volumes aspirated suggest slower gastric emptying. ${ }^{[26]}$ Of note is the fact that we found no significant correlation between a higher volume of 4-hourly nasogastric aspirates and sub- therapeutic rifampicin levels. Data from Ruslami and co-workers previously suggested that the concentrations of rifampicin in ambulant patients receiving rifampicin orally were somewhat higher than those in patients who received drugs (at a similar dose) via a nasogastric tube, suggesting that adsorption of rifampicin to plastics, and potentially to nasogastric tubing, play a role. ${ }^{[27]}$

The association of a lower plasma rifampicin concentration with a lower estimated GFR may very well be spurious, as only approximately $15 \%$ of rifampicin is renally excreted, and theoretically a lower GFR should result in higher plasma concentrations. ${ }^{[19]}$ The small sample size and the fact that patients with an estimated GFR of $<50 \mathrm{ml} / \mathrm{min}$ were excluded confounds this apparent association, as a lower GFR may very well be an indicator of general disease severity.

The sub-therapeutic plasma concentrations observed in our study strongly support the weight of evidence that use of IV rather than oral rifampicin in the critically ill TB patient should become routine practice, given the drug's apparent safety in higher doses. ${ }^{[27,28]}$ Interestingly, in a very recent study, a 33\% higher dose of IV rifampicin $(600 \mathrm{mg}$ v. $450 \mathrm{mg}$ ), led to a three times higher geometric mean area under the time-concentration curve up to 6 
hours after the dose and, importantly, to maximum plasma and cerebrospinal fluid concentrations. ${ }^{[28]}$

The pharmacokinetic profile of isoniazid varies greatly from patient to patient on the basis of acetylator status, as the drug is cleared mostly by acetylation. ${ }^{[4]}$ Slow acetylators obtain higher plasma levels and better therapeutic responses. Interestingly, we found little correlation between acetylator status and plasma levels - in fact, one of the 2 patients with sub-therapeutic isoniazid levels was a slow acetylator.

We observed a mortality rate well below published figures. ${ }^{[4]}$ Although the small sample size complicates meaningful comparison with previous studies, it remains likely that this observation was merely a selection bias, as we only included patients with preserved renal and liver function.

Our study has certain limitations. Our sample size was small and many factors may have influenced the pharmacokinetics, including extremes of weight and days on treatment. ${ }^{[29]}$ The lack of a control group may also be viewed as a limitation of our study. We used historical pharmacokinetic data in our analysis, as it was deemed impractical and unethical to subject 10 healthy volunteers to 7 days of TB treatment, a nasogastric feeding tube and 24 hours of pharmacokinetic sampling.

In conclusion, we found that a fixed-dose combination tablet (Rimstar 4-FDC; Sandoz) given according to weight via a nasogastic tube to patients admitted to the ICU resulted in sub-therapeutic rifampicin plasma concentrations in the majority of patients, whereas the other components had a more favourable pharmacokinetic profile. Patients with sub-therapeutic rifampicin concentrations had a higher APACHE II score and a lower estimated GFR. If confirmed in a larger study, our findings strongly support the use of IV rifampicin in addition to anti-TB drugs given by nasogastric tube in the critically ill TB patient.

\footnotetext{
References

1. Bock N, Reichman LB. Tuberculosis and HIV/AIDS: Epidemiological and clinical aspects (World Pock N, Reichman LB. Tuberculosis and HIV/AIDS: Epidemiological and clinical aspects (World
Perspective). Semin Respir Crit Care Med 2004;25:337-345. [http://dx.doi.org/10.1055/s-2004-829505] Perspective). Semin Respir Crit Care Med 2004;25:337-345. [http://dx.doi.org/10.1055/s-2004-829505]
2. Levy H, Kallenbach JM, Feldman C, Thorburn JR, Abramowitz JA. Acute respiratory failure in active tuberculosis. Crit Care Med 1987;15:221-225. [http://dx.doi.org/10.1097/00003246-198703000-00008] 3. Bernard G, Artigas A, Carlet J, et al. The American-European consensus conference on ARDS: Definitions, mechanisms, relevant outcomes, and clinical trial coordination. Am J Respir Crit Care Med 1994;149:818-824. [http://dx.doi.org/10.1007/BF01704707]

4. Silva DR, Menegotto DM, Schulz LF, Gazzana MB, Dalcin PT. Mortality among patients with tuberculosis requiring intensive care: a retrospective cohort study. BMC Infect Dis 2010;10:54. [http:// dx.doi.org/10.1186/1471-2334-10-54]

5. Tarling MM, Toner CC, Withington PS, Whelpton R, Goldhill DR. A model of gastric emptying using paracetamol absorption in intensive care patients. Intensive Care Med 1997;23:256-260. [http://dx.doi. org/10.1007/s001340050325]
}

6. Russel JA. Management of sepsis. N Engl J Med 2006;355:1699-1713. [http://dx.doi.org/10.1056/ NEJMra043632]

7. Peloquin CA. Therapeutic drug monitoring in the treatment of tuberculosis. Drugs 2002;62:21692183. [http://dx.doi.org/10.2165/00003495-200262150-00001]

8. Pinheiro VG, Ramos LM, Monteiro HS, et al. Intestinal permeability and malabsorption of rifampin 8. Pinheiro VG, Ramos LM, Monteiro HS, et al. Intestinal permeability and malabsorption of rifampin
and isoniazid in active pulmonary tuberculosis. Braz J Infect Dis 2006;10:374-379. [http://dx.doi. org/10.1590/S1413-86702006000600003]

9. World Health Organization. Global Tuberculosis Report 2011. Geneva: World Health Organization, 2011. http://www.who.int/tb/publications/global_report/en (accessed 17 September 2012).

10. Bone RC, Balk RA, Cerra FB, et al. Definitions for sepsis and organ failure and guidelines for the use of innovative therapies in sepsis. Chest 1992;101:1644-1655. [http://dx.doi.org/10.1378/chest.101.6.1644]

1. Knaus WA, Draper EA, Wagner DP, Zimmerman JE. APACHE II: a severity of disease classification system. Crit Care Med 1985;13:818-829. [http://dx.doi.org/10.1097/00003246-198510000-00009]

12. Cockcroft DW, Gault MH. Prediction of creatinine clearance from serum creatinine. Nephron 1976;16:31-41. [http://dx.doi.org/10.1159/000180580]

13. Pai MP, Paloucek FP. The origin of the 'ideal' body weight equations. Ann Pharmacother 2000;34:10661069. [http://dx.doi.org/10.1345/aph.19381]

14. Seifart HI, Donald PR, De Villiers JN, Parkin DP, van Jaarsveld PP. Isoniazid elimination kinetics with protein-energy malnutrition treated for tuberculous meningitis with a four component antimicrobial regimen. Ann Trop Paediatr 1995;15:249-254.

15. Seifart HI, Gent WL, Parkin DP, Van Jaarsveld PP, Donald PR. High-performance liquid chromatographic (HPLC) determination of isoniazid, acetylisoniazid and hydrazine in biological fluids. Journal of Chromatography B Analyt Technol Biomed Life Sci 1995;674:269-275.

16. Parkin DP, Vandenplas S, Botha FJ, et al. Trimodality of isoniazid elimination: phenotype and genotype in patients with tuberculosis. Am J Respir Crit Care Med 1997;155:1717-1722.

17. Parkin DP, Vandenplas M, Vandenplas S, et al. Distribution of acetylator genotypes in the coloured population of the Western Cape region of South Africa. S Afr J Sci 1998;94:404-406.

18. Hall RG, Leff RD, Gumbo T. Treatment of active pulmonary tuberculosis in adults: Current standards and recent advances. Pharmacotherapy 2009;29(12):1468-1481. [http://dx.doi.org/10.1592/ phco.29.12.1468]

19. Long MW, Snider DE Jr, Farer LS. US public health service cooperative trial of three rifampin-isoniazid regimens in treatment of pulmonary tuberculosis. Am Rev Respir Dis 1979;119:879-894.

20. Mcllleron H, Wash P, Burger A, Norman J, Folb PI, Smith P. Determinants of rifampicin, isoniazid, Mcllleron $\mathrm{H}$, Wash P, Burger A, Norman J, Folb PI, Smith P. Determinants of rifampicin, isoniazid,
pyrazinamide and ethambutol pharmacokinetics in a cohort of tuberculosis patients. Antimicrob pyrazinamide and ethambutol pharma

21. Kimerling ME, Phillips P, Patterson P, et al. Low serum antimycobacterial drug levels in non-HIVKimerling ME, Phillips P, Patterson P, et al. Low serum antimycobacterial drug levels in non-HIV-
infected tuberculosis patients. Chest 1998;5:1178-1183. [http://dx.doi.org/10.1378/chest.113.5.1178]

infected tuberculosis patients. Chest 1998;5:1178-1183. [http://dx.doi.org/10.1378/chest.113.5.1178]
22. Chideya S, Winston CA, Peloquin CA, et al. Isoniazid, rifampin, ethambutol, and pyrazinamide pharmacokinetics and treatment outcomes among a predominantly HIV-infected cohort of adults with tuberculosis from Botswana. Clin Infect Dis 2009;48:1685-1694. [http://dx.doi.org/10.1086/599040]

23. Barroso EC, Pinheiro VG, Façanha MC, et al. Serum concentrations of rifampin, isoniazid, and intestinal absorption, permeability in patients with multidrug resistant tuberculosis. Am J Med Hyg 2009;81:322-329.

24. Marcial MA, Carlson SL, Madara JL. Partitioning of paracellular conductances along the ileal cryptvillus axis: a hypothesis based structural analysis with detailed consideration to tight-junction structure-function relationships. J Memb Biol 1984;80:59-70.

25. Peloquin CA, Namdar R, Singleton MD, Nix DE. Pharmacokinetics of rifampicin under fasting conditions, with food, and with antacids. Chest 1999;115:12-18.

26. Stroud $M$, Duncan $H$, Nightingale J. Guidelines for enteral feeding in adult hospital patients. Gut 2003;52(Suppl 7):vii1-vii12. [[http://dx.doi.org/10.1136/gut.52.suppl_7.viil]

27. Ruslami R, Nilland HM, Alisjahbana B, Parwati I, van Crevel R, Aarnoutse RE. Pharmacokinetics and

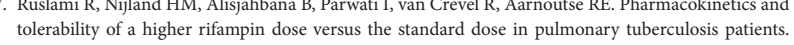
Antimicrob Agents Chemother 2007;51:2546-2551. [http://dx.doi.org/10.1016/S1473-3099(12)702645]

28. Ruslami R, Ganiem AR, Dian S, et al. Intensified regimen containing rifampicin and moxifloxacin for tuberculous meningitis: an open-label, randomised controlled phase 2 trial. Lancet Infect Dis 2013;13(1)27-35. [http://dx.doi.org/10.1016/S1473-3099(12)70264-5]

29. Mcllleron H, Rustomjee R, Vahedi M, et al. Reduced antituberculosis drug concentrations in HIVinfected patients who are men or have low weight: implications for international dosing guidelines. Antimicrob Agents Chemother 2012;56:3232-3238. [http://dx.doi.org/10.1128/AAC.05526-11]

Accepted 5 December 2012 